\title{
Emotional Labor Is Associated With the Mental Health of Respiratory Therapists in Hospitals
}

\author{
Yu-Hua Yan, Chih-Ming Kung, and Shu-Chen Hsing
}

\begin{abstract}
BACKGROUND: Respiratory therapists (RTs) play important roles in providing ventilator support to patients in hospitals. They are on the front line in respiratory cases and work with physicians to help patients survive. However, questions remain regarding whether the mental health conditions at work are protected and secured for RTs. This study aimed to explore the risk factors of mental illness for RTs and to design an app to allow individual RTs to seek assistance at an earlier stage. METHODS: A total of 642 RTs from 107 two-tiered hospitals in Taiwan were randomly selected to complete a 44-item, 5-category questionnaire regarding emotional labor and mental health in 2019. Exploratory factor analysis, the Rasch model, descriptive statistics, the nonparametric Mann-Whitney $U$ test, the Kruskal-Wallis test for unpaired $t$ test, and one-way analysis of variance were performed to examine the demographic characteristics and emotional labor and mental health factors that influence RTs' mental health. An app was then designed to evaluate their mental health status. RESULTS: A total of 352 questionnaires were eligible, with a return rate of $54.8 \%$ (352 of 642 ). About $62.8 \%$ came from medical centers and $37.2 \%$ from regional hospitals. There were $311(88.4 \%)$ women and $41(11.6 \%)$ men, with a mean \pm SD age of $37 \pm 9.5 \mathrm{y}$. Six construct factors were extracted from the responses. The overall reliability of the emotional labor and mental health questionnaire for each subscale beyond 0.70 was evident based on internal consistency and stability in the data. Four risk factors (ie, basic emotional expression, superficial emotional control, emotional diversity extent, and weekly work hours) influenced RT mental health. All findings were applied to design an app for RTs to evaluate their mental health at work. CONCLUSIONS: Four risk factors were verified to influence RT mental health. An app was developed to detect their mental health and allow them to seek assistance at an earlier stage. Key words: respiratory therapist; emotional labor; mental health; working period; medical center; regional hospital. [Respir Care 2021;66(1):50-57. (C) 2021 Daedalus Enterprises]
\end{abstract}

\section{Introduction}

Respiratory therapists (RTs) play important roles in providing ventilatory support to patients in ICUs and hospital emergency departments. RTs are not only trained in

Dr Yan is affiliated with the Department of Medical Research, Tainan Municipal Hospital, Tainan City, Taiwan. Dr Yan is affiliated with the Department of Hospital and Health Care Administration, Chia Nan University of Pharmacy and Science, Tainan City, Taiwan. Dr Kung is affiliated with the Department of Information Technology and Communication, Shih Chien University Kaohsiung, Kaohsiung, Taiwan. Ms Hsing is affiliated with the Department of Respiratory Therapy, ChiMei Medical Center, Yung-kang City, Taiwan.

Supplementary material related to this paper is available at http://www. rcjournal.com. cardiopulmonary care, but they also specialize in the care and therapeutic work of people with pulmonary diseases. They are on the front line in hospitals and provide respiratory care and work with physicians to help in patient survival.

Two decades ago, RTs in Taiwan encountered several challenges and changes, including the introduction of the RT Act in 2001, which defined RTs as independent professionals who are part of the essential workforce ensuring medical

\footnotetext{
The authors have disclosed no conflicts of interest.

Correspondence: Yu-Hua Yan PhD, Department of Hospital and Health Care Administration, Chia Nan University of Pharmacy and Science, No.1, Changda Rd.,Gueiren District, Tainan City, Taiwan. E-mail: 2d0003@mail.tmh.org.tw.
}

DOI: $10.4187 /$ respcare. 07675 
quality in critical care. Until 2013, Taiwanese law ${ }^{1}$ stipulated the fundamental role of RTs in hospitals and ensured that these roles are performed in health care settings. ${ }^{2}$

In recent years, RTs have also played a vital role in the quality of care of elders ${ }^{3}$ and patients experiencing problems associated with increasing levels of air pollution in an industrial society. RTs are the only health care clinicians who continuously receive education and training regarding mechanical ventilation. As a result, ventilators are one of the many health care services provided by RTs to help patients. RTs provide constant monitoring and assessment to patients by modifying ventilator settings as a patient's condition improves or worsens during a treatment regimen. As such, RT-related health care units are frequently found in the ICU and the emergency department. In Taiwan, respiratory care is clinically new but has become indispensable over the past decade. ${ }^{4}$

To obtain the knowledge and skills required for respiratory care in a health care setting, RTs need regular training courses in line with their daily clinical tasks and work load, ${ }^{4}$ such as junior and senior roles of health care. ${ }^{5}$ Furthermore, they are responsible for cost containment and accountability in hospitals. ${ }^{6,7}$

Emotional labor is the process of managing feelings and expressions to fulfill the emotional requirements of a job. Regarding mental health in the workplace, emotional labor is often encountered by front-line medical staff because administrators expect high quality-of-care services from them to meet the organization's goals. RTs and other frontline workers are expected to coordinate, control, or even suppress their emotions regarding the demands of clients, patients, or administrators at work. ${ }^{8,9}$

A conflict between workers' rights and duty is a prevalent concern. ${ }^{10}$ These include focusing on organization-oriented emotion over staff emotion, ${ }^{11}$ hoping that staff focus their efforts properly to satisfy the needs of the organization and clients more than their own needs and then manage (or properly adjust) their work-related emotions at a higher priority. ${ }^{12}$

It is difficult to define emotional labor. ${ }^{13,14}$ Workers should be trained and allowed to practice properly adjusting their emotions without suppressing their internal emotions. Failing to adjust to one's ability to deal with the conflict of work rights and duty carries a substantial burden of long-term emotional labor. Inevitably, this mental health burden will lead to stagnation of work performance. ${ }^{15}$ Conversely, workers who possess positive emotions can create a healthy environment and can maintain the quality of care as well as client satisfaction, whereas negative emotions can increase the worker's burnout and decrease job satisfaction. ${ }^{16,17}$ In this study, we aimed to evaluate the mental health of RTs.

At the Trade Review Conference in 2018, Taiwan was designated by the World Trade Organization as a well-developed country and is among the highest ranked nations in terms of mental-health spending. Numerous organizations

\section{QUICK LOOK}

\section{Current knowledge}

Emotional labor is the process of managing feelings and expressions to fulfill the emotional requirements of a job. Emotional labor is often encountered by frontline medical staff. Failure to adjust the conflict of work rights and duty carries a substantial burden of longterm emotional labor. This mental health burden could lead to stagnation of work performance.

\section{What this paper contributes to our knowledge}

Four risk factors were found to influence the mental health of respiratory therapists at work: basic emotional expression, superficial emotional control, emotional diversity, and weekly work hours.

and institutions have launched a series of mental health promotion programs. ${ }^{18}$ Emotional labor was found to result in emotional exhaustion, negative emotion, burnout at work, ${ }^{19,20}$ and mental health issues, thus directly causing stress, burnout, and low productivity. ${ }^{21-24}$

Lee et $\mathrm{al}^{8}$ disclosed that 4 mental domains, namely basic emotional expression, superficial emotional control, interaction extent, emotional diversity (ie, emodiversity) extent, and deep emotion camouflage, correlated highly and positively with mental health issues at work. The capability to deal with the conflict of work rights and duty is urgently needed by workers, particularly to overcome moderate emotional exhaustion, depersonalization, and low personal accomplishment at work. ${ }^{25,26}$ Cheung et al $^{27}$ used latent profile transition analysis to examine whether emotional labor has changed over time and how to balance lifestyle without conflict of interest at workplace. However, there have been no studies on the risk factors associated with the mental health issues of RTs to date.

Surveys on labor-related emotions for nurses in Taiwan medical centers ${ }^{28}$ and Taiwan Catholic hospitals ${ }^{8}$ lacked information about the mental health of RTs, which motivated us to conduct this study. We aimed to evaluate the risk factors of mental health problems resulting from the emotional labor subscales and the demographic characteristics of RTs in Taiwan, and to design an app to help individual RTs understand their own mental health status, allowing them to seek mental health consultation at an earlier stage.

\section{Methods}

\section{Subjects}

All RTs from 107 2-tiered hospitals in Taiwan (ie, 82 regional hospitals and 25 medical centers) were targeted to 
respond to a 44-item questionnaire. According to the statistics from the Taiwan Society for Respiratory Therapy, 1,521 RTs ( 753 from regional hospitals and 768 from medical centers) were registered in January 2019. Accordingly, if the CI was set at $0.05 \pm 5 \%$ and applied to the population of 1,521 registered RTs, a minimum of 318 respondents were required to reach an adequate sample size. We estimated the percentage of candidate's refusal to respond at $40 \%$; therefore, the minimum number of subjects was 530 [ $n=318 /(1-0.4)]$.

We delivered 6 copies of the 44-item questionnaire to the 107 targeted hospitals. A total of 642 (ie, $6 \times 107$ ) RTs with at least 3 months of experience working in a hospital were randomly selected and invited to complete the emotional labor and mental health survey in March 2019. This study was approved by the Institutional Review Board of Show Chwan Memorial Hospital (approval ID 1080105) before data collection. All hospital and subject identifiers were stripped.

Considerations of RTs rights, interest, privacy, and an informed consent form were taken into account when sending the mail to each hospital along with the 44-item questionnaire. The recipients were allowed to decline and not answer the questionnaire. Respondents were asked to mail the questionnaire to our study clerk in an envelope we provided for that purpose after completion.

\section{Emotional Labor and Mental Health Questionnaire}

The 44-item questionnaire was composed of 2 major parts (ie, emotional labor and mental health), in addition to questions about demographic characteristics. The 24-item emotional labor questionnaire contained those items regarding proper interaction attitudes toward patients designated by the organizations, including 7 items regarding basic emotional expression, 3 items on superficial emotional control, 3 items on interaction extent, 4 items regarding emodiversity extent, and 7 items on deep emotion camouflage. ${ }^{9,11,13,14}$ The contents of these 5 subscales are described below; see the representative items in Table 1 or the link in Reference 29 for detailed information. All of the emotional labor and mental health questions were rated from 1 to 5 (ie, from strongly agree to strongly disagree). Higher scores denote a more severe mental health problem.

Basic emotional expression is the degree to which the respondent expressed genuine heartfelt emotions toward the patient or client during their interaction. Superficial emotional control is the degree to which the respondent reported having hidden emotions from a patient or client during their interaction. Interaction extent includes actively raising questions, discovering health care issues, and participating in the team decisions on patient diagnosis and treatment. Emodiversity extent is the degree to which the respondents expressed emotions that they did not actually feel but were appropriate to express at that time. Deep emotion camouflage involves facing irrationality in a friendly manner, facing your fears, and seeing things from the patient's standpoint.

The second part of the emotional labor and mental health questionnaire was the 20-item mental health scale, which was derived from the World Health Organization selfreporting questionnaire in line with no emotional/mental disease symptoms and with stable and harmonious emotion/mentality as a whole.

\section{Exploratory Factor Analysis of the Questionnaire}

An exploratory factor analysis was performed to determine the number of factors retained in the data. The criterion of factor loadings was set at 0.50 . Furthermore, as suggested by Fornell and Larcker, ${ }^{30}$ we used the validity significance (eg, average variance explained $>0.5$ ) and $t$ values on component reliability $(>0.60)$ at a significant level.

\section{Rasch Analysis}

When ordinal responses from RTs on questions were not congruent with the requirement of equal interval nature for further statistical analysis, we performed Rasch analysis ${ }^{31}$ using the Winsteps software ${ }^{32}$ to transform the ordinal responses into interval logit (ie, log odds) scores ${ }^{33}$ which are suitable for regression analysis to extract the key factors influencing mental health issues among RTs. Furthermore, we examined the construct fitting to the Rasch model's expectation using the criteria of mean square errors in infit and outfit statistics, within an acceptable range of $0.5-1.5$ in comparison to the classic test theory with factor loadings in exploratory factor analysis. ${ }^{34}$

\section{Development of a Mental Health Analysis App for of RTs}

A mobile app was designed by the authors for individual RTs to examine their mental health status, allowing them to seek appropriate consultations and treatments at an earlier stage.

\section{Data Analysis}

SPSS 18.0 for Windows (IBM, Armonk, New York) and MedCalc 9.5.0 for Windows (MedCalc, Ostend, Belgium) were used to perform descriptive statistics, exploratory factor analysis, nonparametric Mann-Whitney $U$ test, KruskalWallis test for unpaired $t$ test, and one-way analysis of variance to examine the demographic characteristics influencing the scores of the RTs' emotional labor and mental health. A box plot was drawn to display the distribution of subscales in comparison. Multiple regression analysis was 
Emotional Labor and RT Mental Health

Table 1. Reliability Analysis and Rasch Analysis

\begin{tabular}{|c|c|c|c|c|c|c|c|c|c|}
\hline \multirow{2}{*}{ Dimension } & \multirow{2}{*}{ No. } & \multirow{2}{*}{ Item } & \multirow{2}{*}{ Loading } & \multirow{2}{*}{ Cronbach $\alpha$} & \multirow{2}{*}{$\begin{array}{l}\text { Rasch } \\
\text { Reliability }\end{array}$} & \multirow{2}{*}{ AVE } & \multirow{2}{*}{$\mathrm{CR}$} & \multicolumn{2}{|c|}{ Rasch Analysis } \\
\hline & & & & & & & & Infit & Outfit \\
\hline \multirow{5}{*}{$\begin{array}{l}\text { Basic emotional } \\
\text { expression }\end{array}$} & A3 & Actively approaching & 0.83 & 0.86 & 0.78 & 0.58 & 0.87 & 1.29 & 1.2 \\
\hline & A4 & $\begin{array}{l}\text { Amiably and pleasantly } \\
\text { interacting }\end{array}$ & 0.80 & & & & & 0.98 & 0.93 \\
\hline & A5 & Kindly smiling & 0.77 & & & & & 0.84 & 0.70 \\
\hline & A2 & $\begin{array}{l}\text { Countenance, attitude, and } \\
\text { tone induced peaceful mind } \\
\text { and trust }\end{array}$ & 0.76 & & & & & 0.78 & 0.67 \\
\hline & $\mathrm{A} 1$ & $\begin{array}{l}\text { The expression, attitude, and } \\
\text { tone provided the sensed } \\
\text { respect }\end{array}$ & 0.66 & & & & & 1.02 & 1.01 \\
\hline \multirow{4}{*}{$\begin{array}{l}\text { Superficial } \\
\text { emotional } \\
\text { control }\end{array}$} & A9 & $\begin{array}{l}\text { Always happily affecting the } \\
\text { work atmosphere }\end{array}$ & 0.75 & 0.78 & 0.77 & 0.49 & 0.79 & 1.16 & 1.17 \\
\hline & A8 & $\begin{array}{l}\text { No affected attitude toward } \\
\text { patients }\end{array}$ & 0.71 & & & & & 1.03 & 1.00 \\
\hline & A10 & Performance reviewing & 0.69 & & & & & 0.88 & 0.84 \\
\hline & A7 & $\begin{array}{l}\text { Emotional expression as a } \\
\text { reference for performance } \\
\text { appraisal }\end{array}$ & 0.65 & & & & & 0.89 & 0.89 \\
\hline \multirow[t]{3}{*}{ Interaction extent } & A12 & $\begin{array}{l}\text { Actively questioning the } \\
\text { discovered team diagnosis } \\
\text { and treatment }\end{array}$ & 0.88 & 0.91 & 0.73 & 0.72 & 0.89 & 1.20 & 0.48 \\
\hline & A13 & $\begin{array}{l}\text { Actively announcing the } \\
\text { discovered care issues and } \\
\text { joining the decision in the } \\
\text { team diagnosis and } \\
\text { treatment }\end{array}$ & 0.87 & & & & & 0.73 & 0.22 \\
\hline & A11 & $\begin{array}{l}\text { Actively participate in the } \\
\text { medical team's decision on } \\
\text { patient diagnosis and } \\
\text { treatment }\end{array}$ & 0.81 & & & & & 0.95 & 0.32 \\
\hline \multirow{4}{*}{$\begin{array}{l}\text { Emodiversity } \\
\text { extent }\end{array}$} & A15 & Exhibiting emodiversity & 0.87 & 0.89 & 0.85 & 0.70 & 0.90 & 1.07 & 0.97 \\
\hline & A17 & Evincing emodiversity & 0.85 & & & & & 0.70 & 0.62 \\
\hline & A16 & $\begin{array}{l}\text { More than one different } \\
\text { emotional state }\end{array}$ & 0.83 & & & & & 1.20 & 1.09 \\
\hline & A14 & Expressing emodiversity & 0.79 & & & & & 0.93 & 0.89 \\
\hline \multirow[t]{3}{*}{$\begin{array}{l}\text { Deep emotion } \\
\text { camouflage }\end{array}$} & A19 & $\begin{array}{l}\text { Facing irrationality in a } \\
\text { friendly manner }\end{array}$ & 0.83 & 0.86 & 0.79 & 0.69 & 0.87 & 0.95 & 0.74 \\
\hline & A18 & $\begin{array}{l}\text { Friendly when facing your } \\
\text { fears }\end{array}$ & 0.83 & & & & & 0.75 & 0.64 \\
\hline & A 20 & $\begin{array}{l}\text { The patient is unreasonable } \\
\text { but still needs to be viewed } \\
\text { from the patient's } \\
\text { standpoint }\end{array}$ & 0.83 & & & & & 1.25 & 0.97 \\
\hline \multirow[t]{8}{*}{ Mental health } & B15 & Deeming events dull & 0.85 & 0.94 & 0.92 & 0.51 & 0.95 & 1.29 & 1.21 \\
\hline & B14 & Deeming the self a failure & 0.82 & & & & & 1.06 & 1.1 \\
\hline & B12 & $\begin{array}{l}\text { Detecting the difficulties in } \\
\text { decision-making }\end{array}$ & 0.80 & & & & & 0.97 & 1.04 \\
\hline & B13 & Affected by the work & 0.80 & & & & & 0.85 & 0.87 \\
\hline & B9 & Being unhappy & 0.79 & & & & & 1.22 & 1.31 \\
\hline & B16 & Feeling self-worthless & 0.77 & & & & & 1.10 & 1.16 \\
\hline & B6 & Feeling anxious & 0.77 & & & & & 0.82 & 0.84 \\
\hline & B18 & Usually feeling weak & 0.76 & & & & & 0.76 & $\begin{array}{l}0.75 \\
\text { tinued) }\end{array}$ \\
\hline
\end{tabular}


Emotional Labor and RT Mental Health

Table 1. Continued

\begin{tabular}{|c|c|c|c|c|c|c|c|c|c|}
\hline \multirow{2}{*}{ Dimension } & \multirow{2}{*}{ No. } & \multirow{2}{*}{ Item } & \multirow{2}{*}{ Loading } & \multirow{2}{*}{ Cronbach $\alpha$} & \multirow{2}{*}{$\begin{array}{l}\text { Rasch } \\
\text { Reliability }\end{array}$} & \multirow{2}{*}{ AVE } & \multirow{2}{*}{$\mathrm{CR}$} & \multicolumn{2}{|c|}{ Rasch Analysis } \\
\hline & & & & & & & & Infit & Outfit \\
\hline & B11 & $\begin{array}{l}\text { Having difficulties in enjoying } \\
\text { the } \operatorname{task}(\mathrm{s})\end{array}$ & 0.76 & & & & & 0.83 & 0.81 \\
\hline & B8 & $\begin{array}{l}\text { Having the difficulties in } \\
\text { being clear-headed }\end{array}$ & 0.76 & & & & & 0.72 & 0.71 \\
\hline & B10 & $\begin{array}{l}\text { Crying more frequently than } \\
\text { usual }\end{array}$ & 0.68 & & & & & 0.86 & 0.8 \\
\hline & B5 & Hand trembling & 0.68 & & & & & 1.31 & 1.17 \\
\hline & B17 & Thinking of suicide & 0.64 & & & & & 1.27 & 1.25 \\
\hline $\begin{array}{l}=\text { average va } \\
=\text { component } \mathrm{r}\end{array}$ & ained & & & & & & & & \\
\hline
\end{tabular}

performed to determine the key factors influencing the mental health of RTs. A significant level of type 1 error was set at 0.05 .

\section{Results}

\section{Demographic Statistics}

A total of 352 questionnaires were eligible, for a return rate of $54.8 \%$ (352 of 642 , greater than the minimum number of subjects determined at the beginning of the study). The demographic data of the RTs are shown in the online supplement (see the supplementary materials at http:// www.rcjournal.com). Approximately $62.8 \%$ of responses came from medical centers and $37.2 \%$ from regional hospitals. There were 311 (88.4\%) women and 41 (11.6\%) men, with a mean $\pm \mathrm{SD}$ age of $37 \pm 9.5 \mathrm{y}$. The frequencies of participants' educational levels were as follows: college (ie, 2-y degree), 17 (4.8\%); university (ie, 4-y degree), 294 (83.5\%); and graduate school, $41(11.6 \%)$.

The number of unmarried (single or divorced) respondents accounted for $61.3 \%$ of the responses, while that of married subjects accounted for 38.6\%. Only the categories of age, marital status, and RT ability presented significant statistical differences in frequency distribution at the hierarchical level. Other detailed information about the sample is provided in the online supplement (see the supplementary materials at http://www.rcjournal.com).

\section{Construct Factors Extracted from the Study Data}

Five construct factors comprising 19 items were extracted from the emotion labor questionnaires, and 13 items formed the mental health scale. All 32 items had factor loadings (ie, an equivalent correlation to the specific factor or domain) $>0.6$ (see Table 1). The overall reliabilities beyond 0.70 for each subscale were evident based on internal consistency and stability in data.

The $t$ values across all domains were significant (Table 1). All reliabilities of domains were above 0.60 , and all average variances were explained. However, one of the superficial emotional control scores with a slighter average variance explained (ie, 0.49 ) was $<0.50$, implying that all domains converged appropriately to validity.

\section{Transforming Ordinal Responses to Interval Logit Scores}

Rasch modeling, which estimates the mental health and perception of the emotional labor of RTs, was performed to transform ordinal responses into interval logit scores and to conduct statistical analyses. We observed that all meansquares of infit and outfit ranged from 0.5 to 1.5 (see the supplementary materials at http://www.rcjournal.com), indicating that all subscales fit the Rasch model with a onedimensional latent construct rather well.

The distributions for each subscale are shown in Figure 1 using box plots. Most RTs with low logits $(<0)$ were mentally healthy. Similarly, RTs appeared to be healthy on the subscale of interaction extent. The higher scores in Figure 1 indicated that more RTs disagree on the subscales of basic emotional expression, superficial emotional control, and deep emotion camouflage.

To inspect the risk factors of mental health derived from the emotional labor subscales and demographic characteristics of RTs in Taiwan, the differences in median scores among the groups were examined, and nonparametric tests were performed (see the supplementary materials at http:// www.rcjournal.com). Only 4 demographic characteristics (ie, hospital type, work tenure, RT hierarchy, and weekly work hours) were present as potential risk factors for poor RT mental health. Nonetheless, only age and RT hierarchy influenced the 2 subscales of interaction extent and 
emodiversity extent (see the supplementary materials at http://www.rcjournal.com).

\section{Risk Factors Influencing the Mental Health of RTs}

To extract the key risk factors substantially influencing the mental health of RTs, we performed multiple regression analysis when the 4 potential factors of demographic characteristics and 5 subscales of emotional labor were involved in the model. After a series of pairwise comparisons of the risk factors with the highest insignificant type 1 error (ie, $>$ 0.05), 4 risk factors were retained in the model: basic emotional expression, superficial emotional control, emodiversity extent, and weekly work hours (see Table 2).

It is worth noting that the 2 subscales of basic emotional expression and superficial emotional control presented a negative relationship with mental health (Table 2), indicating that healthy RTs in Taiwan disagree with the organizational stipulations of proper interaction attitudes toward patients.

\section{An App for Assessing the Mental Health of RTs}

An app was specifically developed to help RTs examine their mental health at work based on the 32 items extracted from the exploratory factor analysis in this study (Table 1).

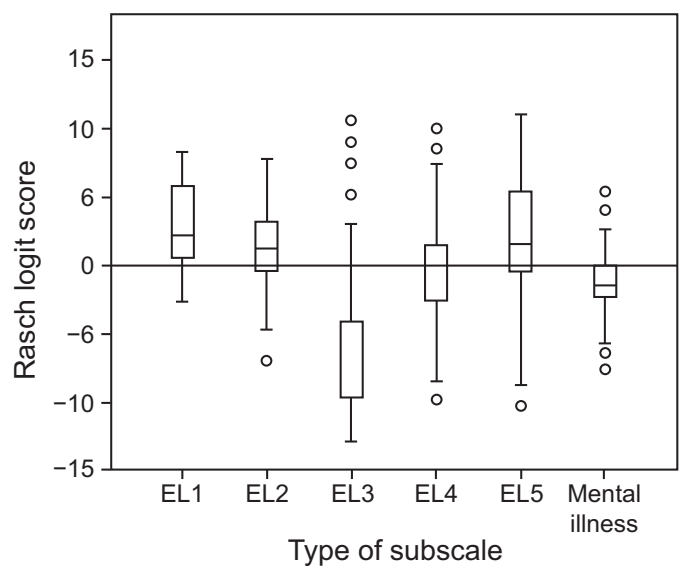

Fig. 1. Scales of mental health and other subscales for emotion labor using Rasch logit scores. EL = emotional labor.
Readers are invited to check our online videos ${ }^{29,35}$ to see a video about the app's intention and operational process for practicing it on their own. A total of 32 eligible items were included in the app. The results with Rasch logit scores on each subscale are automatically calculated by the app and displayed on a user's smartphones. This information could help RTs seek mental health consultations at an earlier stage. It is worth noting that the app is available for RTs to use in the future, but it is limited to RTs in Taiwan because these 32 items were extracted from this study.

\section{Discussion}

Mental problems are situations of the mind that affect daily functioning. In this study, the 4 factors influencing the mental health of RTs in Taiwan were basic emotional expression, superficial emotional control, emodiversity extent, and weekly work hours (Table 2). The perceptions of emotional labor on a 5-point Likert scale for nurses were higher than that for the RTs who participated in this study, indicating that RTs are less burdened by the organizational regulations of proper interaction attitudes toward patients. ${ }^{36,37}$

Although few RTs with mental health problems were found in this study (Fig. 1), chiefs and administrators should frequently and aggressively work to safeguard the mental health of RTs at work. Doing so ensures that quality of care is maintained amid the complexity of the hospital environment. Common situations (eg, sleep disturbance, fatigue, limited social interaction, family alienation, social adaptation impact, and requirements of emotional expression) that can easily lead to poor mental and physical health of RTs in critical care units were elucidated. ${ }^{38}$

Emotional labor reportedly influences the development of poor mental health in the workplace. ${ }^{20,22}$ Our findings regarding basic emotional expression, superficial emotional control, and emodiversity (ie, emotional diversity) were highly and positively correlated with mental health, similar to the findings of Lee et $\mathrm{al}^{8}{ }^{8}$ and are worthy of further investigations in other countries and regions, as well as other disciplines.

Indregard et $\mathrm{al}^{39}$ reported that health care providers and social workers who frequently experience emotional dissonance had higher levels of exhaustion and mental distress, indicating that health care workers are at high risk of mental

Table 2. Multiple Regression Analysis of Risk Factors of Mental Illness for Respiratory Therapists

\begin{tabular}{lccc}
\hline \hline \multicolumn{1}{c}{ Variable } & Unstandardized Coefficient & Standard Error & Standardized $\beta$ \\
\hline Intercept & -1.31 & 0.24 & $<.001$ \\
1. Basic emotional expression & -0.12 & 0.04 & .01 \\
2. Superficial emotional control & -0.16 & 0.06 & .018 \\
3. Emodiversity extent & 0.12 & 0.03 & -0.17 \\
4. Weekly work hours & 0.41 & 0.16 & 0.21 \\
\hline
\end{tabular}


health disorders or illness. Furthermore, some effects on emotional health were reported, such as superficial emotional control, emotional expression, emotional expressionincited emotion disorder, and interaction extent. ${ }^{39}$ These should be addressed within the workplace to prevent the development of issues related to mental health issues. ${ }^{8,40}$

Delgado et $\mathrm{al}^{41}$ stressed that the ability to deal with the conflict of work rights and duty is required for workers who interact with patients and their family members in hospitals. Chen et $\mathrm{al}^{42}$ reported that front-line workers with a strong desire for harmony tend to adopt a more aggressive strategy when confronted with emotional labor to effectively protect themselves from emotional exhaustion. In contrast, other workers experience dissonance between their outward behavior and inner feelings, which likely exhausts their emotional energy. Some effects that correlate with poor mental health need to be avoided or eliminated from workplaces immediately. ${ }^{39,40}$

Both RT hierarchy and tiered hospitals are significantly related to mental health (see the supplementary materials at http://www.rcjournal.com). These have rarely been reported in the literature. It is worth noting that lower RT position and tiered hospitals were associated with poor mental health among staff (see the supplementary materials at http://www.rcjournal.com). The reason for this difference could be explained by the work environment, such as respiratory care centers and respiratory care wards for RTs in medical centers and regional hospitals, respectively. The former typically have $1 \mathrm{RT}$ per 10 beds versus $1 \mathrm{RT}$ per 30 beds for the latter, resulting in the latter experiencing relatively heavier workloads.

Regarding weekly work hours as a risk factor, a significantly negative relationship was observed with mental health problems, indicating that normal work hours set at $40 \mathrm{~h} /$ week improved mental health when compared with the former $46 \mathrm{~h} /$ week (ie, more hours per week resulted in poorer mental health; see the supplementary materials at http://www.rcjournal.com). ${ }^{43}$

The two subscales of basic emotional expression and superficial emotional control presented a negative relationship with mental health, implying that mentally healthy RTs disagree that proper interaction attitudes toward patients are needed. The reasons for this might be that RTs mostly working in the ICU and the emergency department have little interaction with patients compared to other staff (eg, nurses).

We developed an app for individual RTs to aid them in understanding their mental health at work and to enable them to seek mental health consultation at an earlier stage. A video available on YouTube ${ }^{29}$ provides information about the app's intention and operational process.

This study has some advantages, such as finding the key risk factors of poor mental health (Table 2) and providing an app for the assessment of the mental health of RTs at work (Fig. 1). However, it also has some limitations. First, data were gathered only from RTs in Taiwan, so the findings cannot be generalized to other countries, regions, or disciplines, although they are worth studying further in the future, as are the questionnaire and the methodologies applied in this study.

Second, Rasch analysis was performed to transform ordinal responses into interval logit scores, which overcomes the problem of considering ordinal scores as intervals in statistics. The drawback of Rasch analysis is that it is difficult for general researchers to learn Rasch modeling techniques due to the numerous mathematical formulas are that required to understand and perform modeling using Rasch software and to interpret the results.

Third, other factors might substantially affect personal mental health at work, such as organization support, teamwork, and patient safety culture. Future research should include other essential variables to accurately extract additional important factors regarding the mental health of RTs in the future.

Lastly, we applied exploratory factor analysis and regression analysis to extract key construct factors of the mental health of RTs (Table 1). Although Rasch analysis was performed to examine the subscale forming a one-dimensional construct using mean squares of infit and outfit (see the supplementary materials at http://www.rcjournal.com), confirmatory factor analysis is suggested to verify the relationship between variables (ie, mental health problems and key influential factors) in the future.

\section{Conclusions}

Four risk factors influencing the mental health of RTs at work were verified. Based on the factor structure of the emotional labor and mental health questionnaire and 32 eligible items, an app was developed for RTs to evaluate their own mental health status at work. A video is also available online, where the statistics used in this study are displayed. The app is also demonstrated in the video. Readers are invited to watch the video for details about the study process, data arrangement, and the presentation of results.

RTs are not only trained in cardiopulmonary care but they also specialize in the care of people with pulmonary diseases. They are on the front line in respiratory care (particularly during the global COVID-19 pandemic) $)^{44}$ and work with physicians to help patients survive, resulting in concerns regarding their mental health. RTs with mental health problems can pursue appropriate consultations with mental health specialists at an earlier stage based on the mental health assessment done on their smartphones. However, more relevant studies related to the online assessment of the mental and physical health of RTs are encouraged. 


\section{Emotional Labor and RT Mental Health}

\section{ACKNOWLEDGMENTS}

We thank the participating respiratory therapist in completing the questionnaires so that the study could be completed successfully.

\section{REFERENCES}

1. Ministry of Health and Welfare. Medical institution setting standards. Available at: https://www.mohw.gov.tw/cp-3159-24526-1.html. Accessed August 10, 2019

2. Kane C, Terry S. Respiratory therapy career satisfaction. Resp Care 2018;63(Suppl 10):3009976.

3. Wang SH, Kao YH. Discussion on the needs of continuing education courses for respiratory therapists. J Resp Ther 2007;6(1):31-42.

4. Hsieh HK. Respiratory therapist continues education after graduation. J Healthc Qual 2013;20137(5):9-12.

5. Lee JN, Wu MF, Liang CJ, Chou LT, Hsiao HF. The pilot study of innovation of clinical teaching in respiratory therapist-survey of problem solving teaching activities. J Resp Ther 2012;11(2):53-53.

6. Mishoe SC, MacIntyre NR. Expanding professional roles for respiratory care practitioners. Resp Care 1997;42(1):71-91.

7. Becker EA, Hoerr CA, Wiles KS, Skees DL, Miller CH, Laher DS. Utilizing respiratory therapists to reduce costs of care. Respir Care 2018;63(1):102-117.

8. Lee CY, Hsieh PC, Su HF. The relationship between emotional labor and mental health among nurses in Catholic hospitals in Taiwan. Chin J Publ Health 2013;32(2):140.

9. Brotheridge CM, Grandey AA. Emotional labor and burnout: comparing two perspectives of people work. J Vocat Behav 2002;60(1):17-39.

10. Barry B, Olekalns M, Rees L. An ethical analysis of emotional labor. J Bus Ethics 2019;160(1):17-34.

11. Grandey AA. When "the show must go on": surface acting and deep acting as determinants of emotional exhaustion and peer-rated service delivery. Acad Manag J 2003;46(1):86-96.

12. Bhave DP, Glomb TM. Emotional labour demands, wages and gender: a within-person, between-jobs study. J Occup Organ Psych 2009;82 (3):683-707.

13. Grandey AA, Diefendorff JM, Rupp DE. Emotional labor in the 21st century: diverse perspectives on emotion regulation at work. New York: Routledge/Taylor \& Francis Group; 2013.

14. Grandey AA, Melloy RC. The state of the heart: emotional labor as emotion regulation reviewed and revised. J Occup Health Psychol 2017;22(3):407-422

15. Hochschild AR. The managed heart: commercialization of human feeling. Berkeley: University of California Press; 2012.

16. Ashkanasy NM, Härtel CE, Daus CS. Diversity and emotion: the new frontiers in organizational behavior research. J Manage 2002;28(3):307338.

17. Guy ME, Newman MA, Mastracci SH. Emotional labor: putting the service in public service. Armonk, NY: ME Sharpe; 2008.

18. Dimoff JK, Kelloway EK. With a little help from my boss: the impact of workplace mental health training on leader behaviors and employee resource utilization. J Occup Health Psychol 2019;24(1):4-19.

19. Alicia AG. Emotion regulation in the workplace: a new way to conceptualize emotional labor. J Occup Health Psychol 2000;5(1):95-110.

20. Ashforth BE, Humphrey RH. Emotional labor in service roles: the influence of identity. Acad Manag Rev 1993;18(1):88-115.

21. Liu YH. Exploring relationships among emotional labor, job stress, and coping behaviors in nurses. J Health Sci 2009;11(2):98-115.

22. Morris JA, Feldman DC. The dimensions, antecedents, and consequences of emotional labor. Acad Manag Rev 1996;21(4):986-1010.
23. Wu TY. Abusive supervision and emotional exhaustion: the mediating effects of subordinate justice perception and emotional labor. Chinese J Psychol 2008;50(2):201-221.

24. Ho HC, Chang SH, Tsao JY, Chang MF, Chen YH, Yang T. The relationship between job stress and physical-mental health among hospital staff. Chinese J Occup Med 2010;17(4):239-252.

25. Marquis EB, Kim S, Alahmad R, Pierce CS, Robert LP, Jr. Impacts of perceived behavior control and emotional labor on gig workers. Companion of the 2018 ACM Conference on Computer Supported Cooperative Work and Social Computing, October 2018: 241-244

26. Tsai YH, Chen KW, Hsiao HF, Fang TP, Chien MY, Wan GH. Job burnout associated with work satisfaction in hospital respiratory therapists. J Resp Ther 2016;15(2):1-13.

27. Cheung F, Lun V, Cheung MWL. Emotional labor and occupational well-being: latent profile transition analysis approach. Front Psychol 2018;3(9):1084.

28. Lin SP. A study of the development of emotional labour loading scale. Sun Yat-Sen Manag Rev 2000;8(3):427-447.

29. Yan YH. Introduction to mental health for MP4 video for respiratory therapists in Taiwan. Available at: https://www.youtube.com/watch? $\mathrm{v}=6 \mathrm{v} \_$eMDeGnUI\&feature=youtu.be. Accessed May 1, 2020.

30. Fornell C, Larcker DF. Structural equation models with unobservable variables and measurement error. J Mark Res 1981;18(1):39-50.

31. Rasch G. Probabilistic models for some intelligence and attainment tests. Chicago: University of Chicago Press; 1960.

32. Linacre JM. Winsteps Rasch measurement computer program (version 4.0.1). Chicago: Winsteps.com; 2006.

33. Bond TG, Fox CM. Applying the Rasch model: fundamental measurement in the human sciences, 2nd ed. Mahwah, NJ: Erlbaum; 2007.

34. Linacre LM. What do infit and outfit, mean-square and standardized mean? Rasch Meas Trans 2003;16(2):878.

35. Yan YH. Online assessment of mental illness for respiratory therapists in Taiwan. Available at: http://www.healthup.org.tw/irs/irsin.asp? type $1=90$. Accessed May 1, 2020

36. Park HS, Yoo YG. The moderating effect of social support on the relationship between emotional labor and nursing performance in general hospital. J Korean Acad Nurs Adm 2019;25(2):136-145.

37. Jung JY, Park MJ. The effects of emotional labor, resilience, and nursing work environment on turnover intentions of comprehensive nursing care medical service nurses. J Digit Convergence 2019;17(3):281-290.

38. Lin SH, Liao WC, Chen MY, Fan JY. The impact of shift work on nurses' job stress, sleep quality and self-perceived health status. J Nurs Manag 2014;22(5):604-612.

39. Indregard AMR, Knardahl S, Nielsen MB. Emotional dissonance, mental health complaints, and sickness absence among health-and social workers: the moderating role of self-efficacy. Front Psychol 2018;9:592.

40. Brotheridge CM, Lee RT. Testing a conservation of resources model of the dynamics of emotional labor. J Occup Health Psych 2002;7(1):57-67.

41. Delgado C, Roche M, Fethney J, Foster K. Workplace resilience and emotional labour of Australian mental health nurses: results of a national survey. Int J Ment Health Nurs 2020;29(1):35-46.

42. Chen KY, Chang CW, Wang CH. Frontline employees' passion and emotional exhaustion: the mediating role of emotional labor strategies. Int J Hosp Manage 2019;76(1):163-172.

43. Virtanen M, Jokela M, Madsen IE, Hanson LLM, Lallukka T, Nyberg ST, et al. Long working hours and depressive symptoms: systematic review and meta-analysis of published studies and unpublished individual participant data. Scand J Work Environ Health 2018;44(3):239-250.

44. World Health Organization. Coronavirus disease 2019 (COVID-19) situation report - 143. Available at: https://www.who.int/docs/defaultsource/coronaviruse/situation-reports/20200611-covid-19-sitrep-143. pdf?sfvrsn=2adbe568_4. Accessed June 12, 2020. 